\title{
O COMPLEXO METAMÓRFICO CAMPO BELO (CRÁTON SÃO FRANCISCO MERIDIONAL): UNIDADES LITODÊMICAS E EVOLUÇÃO TECTÔNICA
}

\author{
RINALDO AFRÂNIO FERNANDES ${ }^{1 *} \&$ MAURÍCIO ANTÔNIO CARNEIRO ${ }^{2 *}$
}

\begin{abstract}
RESUMO O Complexo Metamórfico Campo Belo, na região estudada, é constituído por rochas gnáissicas, anfibolíticas e metaultramáficas que foram intrudidas por gabronoritos, granitóides e gabros. Registros esparsos de rochas quartzíticas são encontrados localmente. Esses tipos petrográficos foram englobados em sete unidades litodêmicas, denominadas da seguinte forma: 1) Unidade Gnáissica, 2) Unidade Anfibolítica, 3) Unidade Metaultramáfica, 4) Unidade Quartzítica, 5) Unidade Gabronorítica, 6) Unidade Granitóide (l.s.) e 7) Unidade Gabróica. A Uni dade Gnáissica constitui o embasamento cristalino da região e serve de encaixante (ou embasamento ?) para as demais unidades litodêmicas. A Unidade Anfibolítica apresenta indícios petrológicos que sugerem uma trajetória de resfriamento isobárico e, juntamente, com a Unidade Gnáissica têm hiperstênio metamórfico modal. Características metamórficas, da fácies granulito, também estão presentes nas rochas das Unidades Metaultramáfica e Quartzítica que, a exemplo das rochas das Unidades Gnáissica e Anfibolítica, estão retrometamorfisadas para as fácies anfibolito e, posteriormente, xisto verde. As Unidades Gabronorítica, Granítica (s.l.) e Gabróica, por apresentarem, apenas, paragêneses da fácies xisto verde, foram colocadas, na crosta, após os eventos tectonotermais que deram origem às paragêneses das fácies granulito e anfibolito. Essa dualidade, em relação à intensidade do grau metamórfico, traduziria, em parte, a complexa história evolutiva da região, a qual relacionar-seia à ocorrência de eventos magmáticos (meso-e neoarqueanos) e epirogênicos após o Neoarqueano.
\end{abstract}

Palavras-chave: Cráton São Francisco Meridional, Complexo Metamórfico Campo Belo, Terrenos de Alto Grau, Evolução Tectônica, Arqueano.

\begin{abstract}
THE CAMPO BELO METAMORPHIC COMPLEX (SOUTHERN SÃO FRANCISCO CRATON): LITHODEMIC UNITS AND TECTONIC EVOLUTION The Campo Belo Metamorphic Complex in the study area is constituted by gneissic, amphibolitic and metaultramafic rocks intruded by gabbronorites, granitoids and gabbros. Scattered records of quartzitic rocks are locally found. These petrographic types were grouped in seven lithodemic units, named as follows: 1) Gneissic Unit, 2) Amphibolitic Unit, 3) Metaultramafic Unit, 4) Quartzitic Unit, 5) Gabbronoritic Unit, 6) Granitoid Unit (l.s.), and 7) Gabbroic Unit. The Gneissic Unit constitutes the regional crystalline basement and acted as host rock (or basement?) for the other lithodemic units. The Amphibolitic Unit presents petrologic evidences that suggest an isobaric cooling history and, as well as the Gneissic Unit, it contains modal hypersthene. Metamorphic characteristics of the granulite facies are also recognized in the rocks of the Metaultramafic and Quartzitic Units; similarly to what happened with the rocks of the Gneissic and Amphibolitic Units, the rocks were retrometamorphosed to the amphibolite and later to the greenschist facies. The Gabbronoritic, Granitic (s.l.) and Gabbroic Units, once presenting paragenetic assemblages characteristic of the greenschist facies only, were emplaced in the crust after the tectonothermal events that generated the paragenetic sequences of the granulite and amphibolite facies. This duality, regarding the metamorphic grade intensity, would in part express the complex evolutionary history of the area, which would be related to the occurrence of magmatic (Mesoand Neoarchean) and epeirogenic events after the Neoarchean.
\end{abstract}

Keywords: Southern São Francisco Craton, Campo Belo Metamorphic Complex, High Grade Terranes, Tectonic Evolution, Archaean.

INTRODUÇÃo Como se sabe, os terrenos arqueanos do Cráton São Francisco Meridional (Fig. 1) são formados por gnaisses e granitóides (de composição TTG), seqüência supracrustal do tipo greenstone belts (Supergrupo Rio das Velhas) e enxames de diques máficos, variavelmente metamorfisados (e.g., Alkmim et al. 1993; Teixeira et al. 1996; Pinese 1997). Muitos estudos, enfocando a seqüência supracrustal, têm sido realizados. As demais unidades, especialmente aquelas da porção félsica da crosta arqueana, não têm recebido a mesma atenção, porque essas não têm o mesmo significado econômico daquelas. Entretanto, é o substrato siálico que tem guardado a gama total dos registros petrológicos e isotópicos da evolução crustal de terrenos correlatos [e.g., Complexo Napier - Black et al. (1983); oeste da Groenlândia - Chadwick \& Coe (1976), Moorbath et al. (1975, 1986); Complexo Lewisian - Hamilton et al. (1979), Rollinson \& Windley (1980); Complexo Jequié - Figueiredo \& Barbosa (1992)]. Especialmente, no caso em estudo, muito pouco se sabe a respeito da gênese da crosta siálica do Cráton São Francisco Meridional, destacando-se, nesta lacuna, a quantificação e a subsequente caracterização geográfica, geológica (s.l.), litodêmica e isotópica dos complexos metamórficos que a constituem. Questões básicas, tais como o limite entre os complexos, sequer foram abordadas. Assim, no sentido de contribuir para o conhecimento geológico desta crosta siálica arqueana apresenta-se, neste trabalho, uma caracterização petrológica e, ao mesmo tempo, litodêmica das principais unidades do Complexo Metamórfico Campo Belo. A região estudada (Figs. 1 e 2) engloba alguns municípios da porção centro-sul do Estado de Minas Gerais e está localizada entre as cidades de Santo Antônio do Amparo, a sudeste, e Candeias, a noroeste, abrangendo uma área de $1200 \mathrm{~km}^{2}$. Além desta caracterização petrológica/litodêmica, tentar-se-á estabelecer relações genéticas entre os principais litotipos, processos metamórficos, eventos tectonotermais e as prováveis correlações tectono-litodêmicas com outros terrenos da mesma porção cratônica.

EVOLUÇÃO DOS CONHECIMENTOS As primeiras descrições das rochas que compõem a crosta siálica arqueana do Cráton São Francisco Meridional foram feitas por Barbosa (1954). Esse autor introdu- ziu o termo Série Barbacena para designar um conjunto de rochas xistosas, de natureza básica, extremamente granitizadas, situadas na região de Barbacena (Fig. 1), as quais considerou como formadas em ambiente geossinclinal. Para Barbosa (1954) essa série estaria situada, estratigraficamente, sobre a Série Mantiqueira, conhecida hoje como Gnaisse Piedade (Ebert 1958) e abaixo da Série Minas, atualmente Supergrupo Minas (Dorr II 1969). Oliveira (1954) propôs que a Série Barbacena fosse chamada de Série Pré-Minas. Ebert (1956) identificou duas formações na Série Barbacena de Barbosa (1954) e atribuiu a elas as denominações de Formação Lafaiete e Formação Barbacena. A primeira, por estar menos granitizada que a segunda, teria na opinião de Ebert (1956) uma idade mais jovem. Com a descoberta de uma discordância angular e erosiva entre a Série Pré-Minas e a Série Minas (e.g., Rynearson et al. 1954), Dorr II et al. (1957) introduziram a expressão Série Rio das Velhas em substituição à Série PréMinas. Pires (1977) retomou, parcialmente, as idéias de Barbosa (1954) e englobou, no Grupo Barbacena, as rochas da Formação Lafaiete e da Série Rio das Velhas. Schorscher (1979), após identificar uma sequêencia basal de komatiítos na Série Rio das Velhas de Dorr II et al. (1957), elevou essa série à condição de Supergrupo. Machado Filho et al. (1983), retomando o estudo da crosta siálica arqueana do Cráton São Francisco Meridional (Fig. 1), dividiram-na em dois complexos metamórficos: Barbacena e Divinópolis. Para esses autores, o Complexo Barbacena (que englobaria os complexos metamórficos Belo Horizonte e Bonfin), situado na parte oriental dessa porção do cráton (Fig. 1), seria constituído por metatexitos com paleossomas xistosos básicos e ultrabásicos "e neossomas granodioríticos e graníticos, de idade fundamentalmente arqueana, mas parcialmente retrabalhados no Ciclo Transamazônico. Rochas charnockíticas, anfibolíticas, magnetititos, gnaisse facóidal e granito estanífero teriam ocorrência mais restrita nesse complexo. Já o Complexo Divinópolis, situado na metade ocidental da região em questão (Fig. 1), seria caracterizado por um conjunto de granitóides, cisalhados em regime dúctil (similares àqueles do Complexo Barbacena) e raros encraves de metaultrabasitos e magnetititos. Teixeira et al. (1996), denominaram de Complexo Metamórfico Campo Belo a crosta siálica, predominante- 


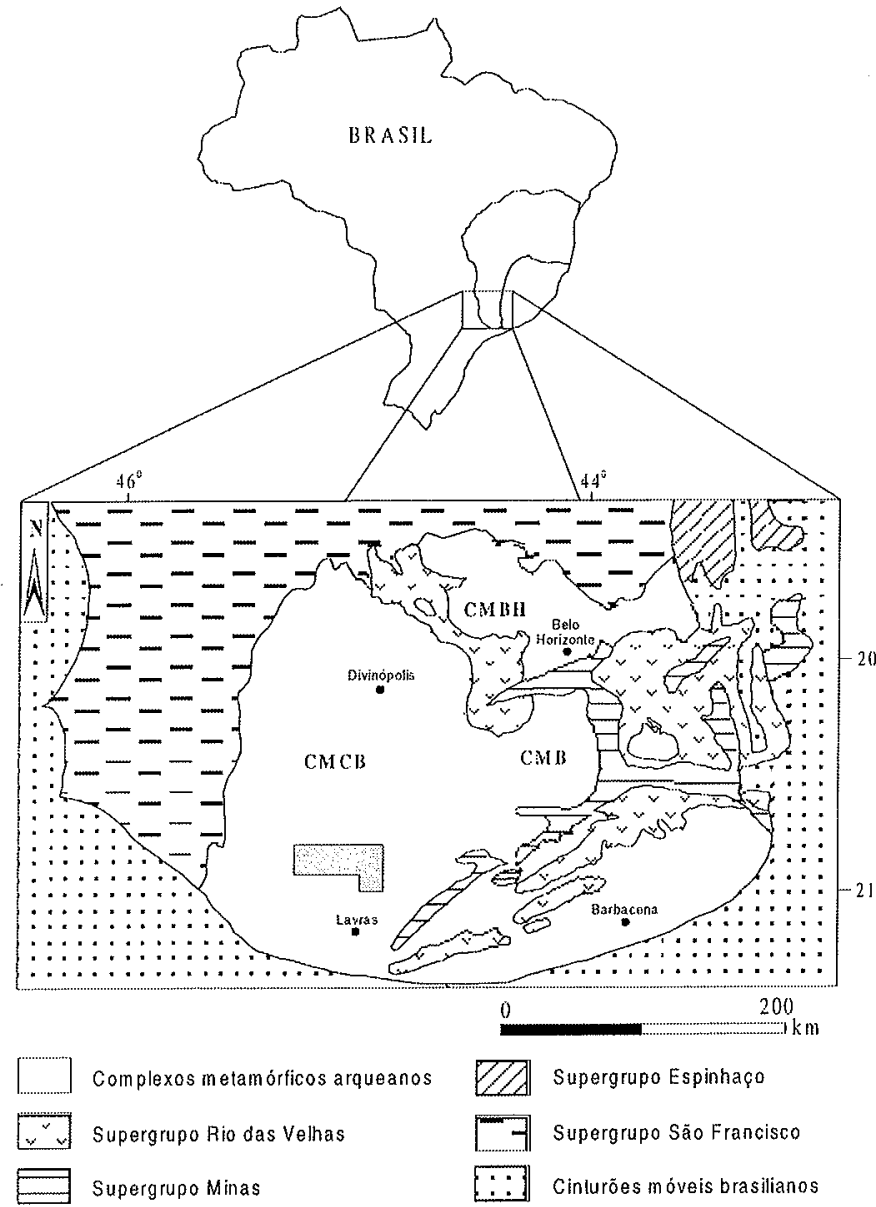

Figura 1 - Mapa geológico (simplificado) do Cráton São Francisco Meridional, localizando os complexos metamórficos Belo Horizonte (CMBH), Bonfim $(C M B)$, Campo Belo $(C M C B)$, as seqüências supracrustais, cinturões móveis adjacentes e a região estudada (polígono cinza). mente arqueana, que aflora a ocidente do Complexo Metamórfico Bonfim (Fig. 1), englobando nessa definição os complexos Divinópolis e Barbacena, reconhecidos originalmente na região por Machado Filho et al. (1983). Pinese (1997), na região de Lavras (Fig. 1), relatou a ocorrência de dois eventos de magmatismo básico fissural, relacionados respectivamente ao Neoarqueano e ao Paleoproterozóico. Trabalhos mais recentes, desenvolvidos por Carneiro et al. (1996a; b; 1997a; b; c;1998a; b), Carvalho Júnior et al. (1997; 1998), Fernandes et al. (1997; 1998), Fernandes \& Carneiro (1999), Oliveira (1999), Corrêa da Costa (1999) e Carvalho Júnior \& Carneiro (1999), têm revelado outras particularidades acerca da constituição petrográfica do Complexo Metamórfico Campo Belo e de sua evolução tectônica.

UNIDADES LITODÊMICAS A região estudada é formada por rochas metamórficas e, subordinadamente, ígneas (Fig. 2), pertencentes ao Complexo Metamórfico Campo Belo (Teixeira et al. 1996). No que se refere à nomenclatura dessas rochas, os litotipos ígneos foram classificados segundo as recomendações de Streckeisen (1974a; b) e os litotipos metamórficos seguiram as recomendações de Winkler (1981), Turner (1981), Yardley (1993) e Bucher \& Frey (1994). Quanto à sistematização litodêmica das unidades, observaram-se as recomendações do Código Brasileiro de Nomenclatura Estratigráfica e, principalmente, a contribuição de Hattin (1991), no que se refere às rochas intrusivas altamente deformadas e/ou metamorfisadas, mas geneticamente associadas. Sendo assim, as rochas, da região em estudo, foram englobadas em sete unidades litodêmicas, denominadas da seguinte forma: 1) Unidade Gnáissica, 2) Unidade Anfibolítica, 3) Unidade Metaultramáfica, 4) Unidade Quartzítica, 5) Unidade Gabronorítica, 6) Unidade Granítica (s.l.) e 7) Unidade Gabróica. Esta ordem obedece a critérios cronológicos relativos de formação das unidades.

Unidade Gnáissica As rochas gnáissicas têm predominância na região estudada (Fig. 2) e variam, petrograficamente, de tonalito a granito. Por causa disso, e devido à presença metamórfica de ortopiroxênio modal, as variedades gnáissicas foram classificadas como: 1) hiperstênio-biotita-hornblenda gnaisse tonalítico; 2) hiperstênio-diopisídio-biotita gnaisse tonalítico; 3) hiperstênio-biotitahornblenda gnaisse granítico e 4) hiperstênio-diopisídio-biotita gnaisse granítico. De maneira geral, as medidas da foliação dos gnaisses mostram uma direção geral NW, mas ocorrem grandes lineamentos onde a foliação inflete para NE (mega-zona de cisalhamento ?). Estas estruturas (foliações) apresentam ângulos de mergulho que variam entre $70^{\circ}$

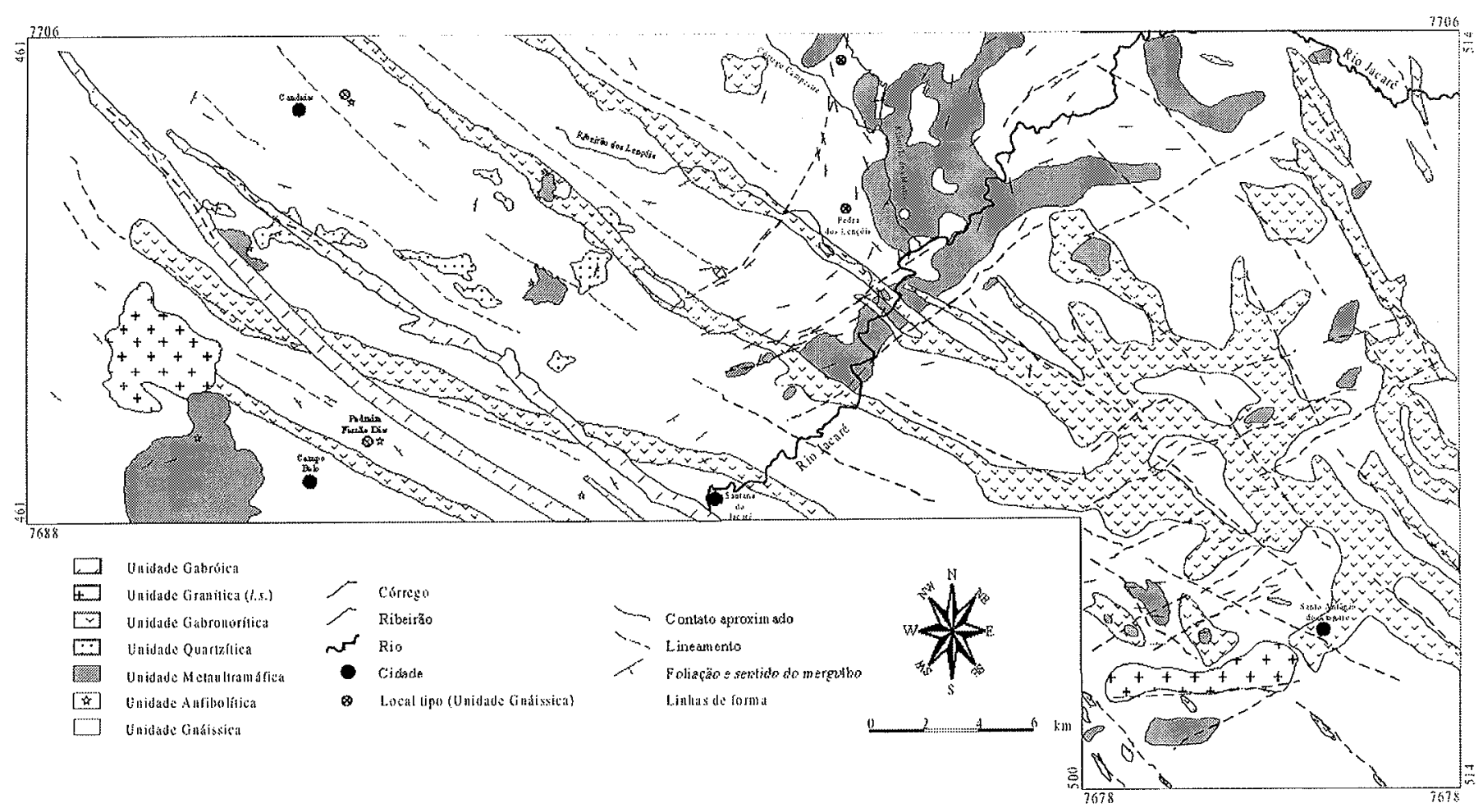

Figura 2 - Mapa geológico simplificado da região em estudo. 
a $85^{\circ}$ e são concordantes com outras estruturas do Cráton São Francisco Meridional (e.g., Endo \& Carneiro 1996a, Endo 1997, Carneiro et al. 1998a, Alkmim et al. 1993, Alkmim \& Marshak 1998). Segundo a direção NE ocorrem também zonas de cisalhamento delgadas, as quais geram rochas miloníticas, altamente magnéticas (magnetitito), que se distribuem por toda a região em apreço. Além disso, as rochas gnáissicas constituem o embasamento cristalino da região e serviram de encaixantes para os eventos magmáticos posteriores e substrato siálico para a deposição das sequiências supracrustais geradas do Neoarqueano ao Neoproterozóico (Fig. 1).

HIPERSTENNIO-BIOTITA-HORNBLENDA GNAISSE TONALÍTICO O local tipo dessa variedade é a Pedreira Fernão Dias nas imediações da Cidade de Campo Belo (Fig. 2). A rocha tem cor cinza, granulação média e texturas hétero-granoblástica (Fig. 3a), lepidoblástica e nematoblástica. No campo, esse gnaisse apresenta um bandamento caracterizado pela intercalação de bandas leucocráticas quartzofeldspáticas contínuas e melanocráticas descontínuas (piroxênio, biotita e anfibólio). Os feldspatos são representados pelo plagioclásio antipertítico (Fig. 3a), perfazendo $\sim 40 \%$ do volume total da rocha, e, subordinadamente, pelo microclínio $(\sim 10 \%$ do volume total da rocha) que está sericitizado. Quartzo representa cerca de $20 \%$ do volume total da rocha. Hiperstênio perfaz $\sim 5 \%$ do volume da rocha e é um mineral metamórfico. Hornblenda $(\sim 15 \%)$, em alguns casos, constitui coronas de reação no ortopiroxênio, noutros, ocorre associada à biotita e são orientadas segundo o plano de foliação da rocha. A biotita $(\sim 10 \%)$, quando em contato com o microclínio, apresenta crescimento simplectítico com quartzo, noutros casos, altera-se para clorita. Opa$\cos$, zircão e apatita são as fases acessórias comuns.

HIPERSTÊNIO-DIOPISIDIO-BIOTITA GNAISSE TONALITICO O local tipo dessa variedade é conhecido como Pedra dos Lençóis (Fig. 2). A rocha apresenta cor cinza, granulação média e texturas granoblástica e lepidoblástica (Fig. 3b). Mostra bandas melanocráticas, constituídas por piroxênios (clino + orto) e biotita, intercaladas com bandas leucocráticas quartzo-feldspáticas. O plagioclásio ( 35-40\%) é antipertítico e, quando em contato com o microclínio, mostra crescimento de quartzo mimerquítico. Quartzo perfaz cerca de $20 \%$ do volume total da rocha. O microclínio ( 10\%), por sua vez, ocorre subordinadamente ao plagioclásio e está micropertitizado. Os piroxênios são representados pelo hiperstênio $(\sim 5 \%)$ e pelo diopisídio $(\sim 10 \%)$ e, muitas vezes, ambos alteram-se para biotita e epidoto (Fig. 3b). A biotita $(\sim 15 \%)$ ocorre como produto de alteração dos piroxênios, apresenta crescimento de quartzo mimerquítico quando próxima ao microclínio e altera-se para clorita, estilpnomelano e sericita. Opacos, apatita e zircão são os minerais acessórios presentes.

HIPERSTENNIO-BIOTITA-HORNBLENDA GNAISSE GRANÍTICO O local tipo dessa variedade é uma pedreira situada nas imediações da cidade de Candeias (Fig. 2). A rocha apresenta cor cinza esverdeada, porções migmatizadas de coloração rosa, textura granoblástica e, subordinadamente, lepidoblástica e nematoblástica (Fig. 3c). O bandamento gnáissico, pouco visível, é marcado pela presença de minerais máficos (piroxênio, biotita e anfibólio) agrupados e orientados em faixas descontínuas e intercaladas com bandas leucocráticas quartzo-feldspáticas contínuas. O plagioclásio é antipertítico e pode representar entre 20 e $40 \%$ do volume total da rocha. O microclínio está sericitizado e perfaz entre 40 e $50 \%$, podendo atingir até $60 \%$ do volume total da rocha. Quartzo atinge de 20 a $25 \%$ do volume da rocha. $O$ hiperstênio é um mineral metamórfico e contribui com $\sim 5 \%$ do volume total. A hornblenda $(\sim 10 \%)$ associa-se à biotita $\mathrm{e}$, por vezes, envolve o piroxênio. A biotita $(\sim 5 \%)$ altera-se para clorita. Apatita, zircão e opacos são minerais acessórios.

HIPERSTENNIO-DIOPISIDIO-BIOTITA GNAISSE GRANITICO O local tipo para essa variedade gnáissica ocorre entre o Córrego Campestre e o Ribeirão dos Motas (Fig. 2). A rocha tem coloração cinza, granulação média, textura granoblástica e, subordinadamente, lepidoblástica (Fig. 3d). O bandamento gnáissico é pouco expressivo, porém, representado pela intercalação de bandas melanocráticas, compostas pelos piroxênios (orto + clino) e biotita e bandas leucocráticas quartzo-feldspáticas. $O$ microclínio está micropertitizado e perfaz cerca de $40 \%$ do volume total da rocha. O plagioclásio é antipertítico e representa entre 20 e $25 \%$ do volume total. Quartzo representa cerca de
$20 \%$. Os piroxênios alteram-se para biotita e epidoto, porém, reconhece-se o hiperstênio $(\sim 5 \%)$ e o diopisídio $(\sim 10 \%)$. A biotita $(\sim 10$ $15 \%$ ), quando em contato com o microclínio, apresenta crescimento de quartzo mimerquítico, noutros casos, altera-se para clorita e estilpnomelano (Fig. 3e). Zircão, opacos e apatita representam a mineralogia acessória.

Unidade Anfibolítica Ocorrências de anfibolito são comuns na área estudada mas, em virtude dos seus reduzidos tamanhos, não têm representação no mapa geológico da região estudada (Fig. 2). De maneira geral, essas ocorrências estão encaixadas nos gnaisses, paralelas ao bandamento, e são encontradas na forma de diques deformados, boudins e, às vezes, como encraves em fases migmatíticas das rochas gnáissicas (Fig. 3f). São rochas melanocráticas, de composição básica, apresentam cor escura em tons cinza-esverdeados e granulação média a grossa. Apresentam arranjo textural condizente com o tipo héterogranoblástico e, subordinadamente, cumulático. Além disso, por exibirem uma foliação mineral bastante proeminente, onde se nota a orientação de minerais máficos (clino- e ortopiroxênio, biotita e hornblenda), mostram texturas do tipo lepidoblástica e nematoblástica, além de aglomerados de cristais, ora de piroxênio, ora de anfibólio (Fig. 4a). Essas rochas são classificadas petrograficamente como hiperstênio anfibolito. A hornblenda é o principal constituinte e perfaz cerca de $50 \%$ do volume total da rocha, podendo atingir, raras vezes, até $70 \%$. Além disso, em alguns casos, os cristais apresentam natureza ígnea remanescente, porém noutros, ocorrem como produto da transformação dos piroxênios. O plagioclásio, segundo maior componente $(\sim 20-30 \%)$, está sericitizado e saussuritizado e, por isso, mostra maclas fantasmas. Os piroxênios, hiperstênio $(\sim 5 \%)$ e augita $(\sim$ $5 \%$ ), estão fraturados e exibem franjas de anfibólio em suas bordas, efeito da uralitização. Uma particularidade importante, nestas rochas, é a presença de coronas de augita à volta do hiperstênio. Este fato, que tem implicações tectônicas, será discutido mais a diante. Biotita é rara, mas ocorre associada à hornblenda $\mathrm{e}$, às vezes, altera-se para clorita. Apatita, zircão e opacos ocorrem como as fases acessórias principais Quartzo $(\sim 5 \%)$ e epidoto são produtos da transformação dos piroxênios.

Unidade Metaultramáfica A essa Unidade corresponde uma sequiência de rochas metaultramáficas acamadadas, amplamente distribuídas na região em questão. Todavia, é entre o Ribeirão dos Motas e o Rio Jacaré (Fig. 2) que ocorre a maior densidade de afloramentos, os quais constituem um corpo rochoso, encaixado nos gnaisses, orientado segundo a direção NE-SW e denominado de Sequêencia Acamadada Ribeirão dos Motas (SARM, Carneiro et al. 1996a). As rochas metaultramáficas são ultramelanocráticas, do tipo metaperidotito e metapiroxenito, com texturas ígneas reliquiares (cumulática) e paragêneses metamórficas de fácies granulito, mas retrometamorfisadas para as fácies anfibolito e xisto verde. Todavia, as rochas metaultramáficas constituem um assunto a parte que demanda maiores discussões e, portanto, não terão tratamento detalhado nesse trabalho. Maiores informações podem ser encontradas em Carneiro et al. (1996a; 1997a; b; c), Carvalho Júnior et al. $(1997 ; 1998)$, Corrêa da Costa (1999), Oliveira (1999) e Carvalho Júnior \& Carneiro (1999).

Unidade Quartzítica Esta unidade aflora próxima à Cidade de Candeias (Fig. 2) e é representada por um granada-sillimanitaquartzito, ocorrendo de forma esparsa e de relacionamento estratigráfico não muito claro com os gnaisses (Corrêa da Costa 1999). Todavia, esse quartizito é intrudido por diques da Unidade Gabronorítica. Apresenta uma foliação milonítica que inflete para NEE e SEE, mergulhando para SE e SW (ângulos entre $40^{\circ}$ e $60^{\circ}$ ), e indicadores de movimento normal com componente direcional sinistral. Os arranjos texturais são do tipo granoblástico e decussado (cristais de sillimanita; Fig. 4b). O quartzo é o maior constituinte, perfazendo $60-70 \%$ do volume total da rocha. A sillimanita $(\sim 20 \%)$ ocorre como cristais fibrolíticos e porfiroblásticos e mostra alteração para muscovita. A granada apresenta inclusões de rutilo e alteração para óxido de ferro $(\sim 5-10 \%)$. A muscovita $(\sim 5 \%)$ ocorre como plaquetas intersticiais aos grãos de quartzo e transforma-se para sericita e pirofilita. Zircão, apatita e opacos ocorrem como minerais acessórios.

Unidade Gabronorítica A essa unidade correspondem os diques máficos orientados segundo a direção N65-70W (Fig. 2), intrusivos 

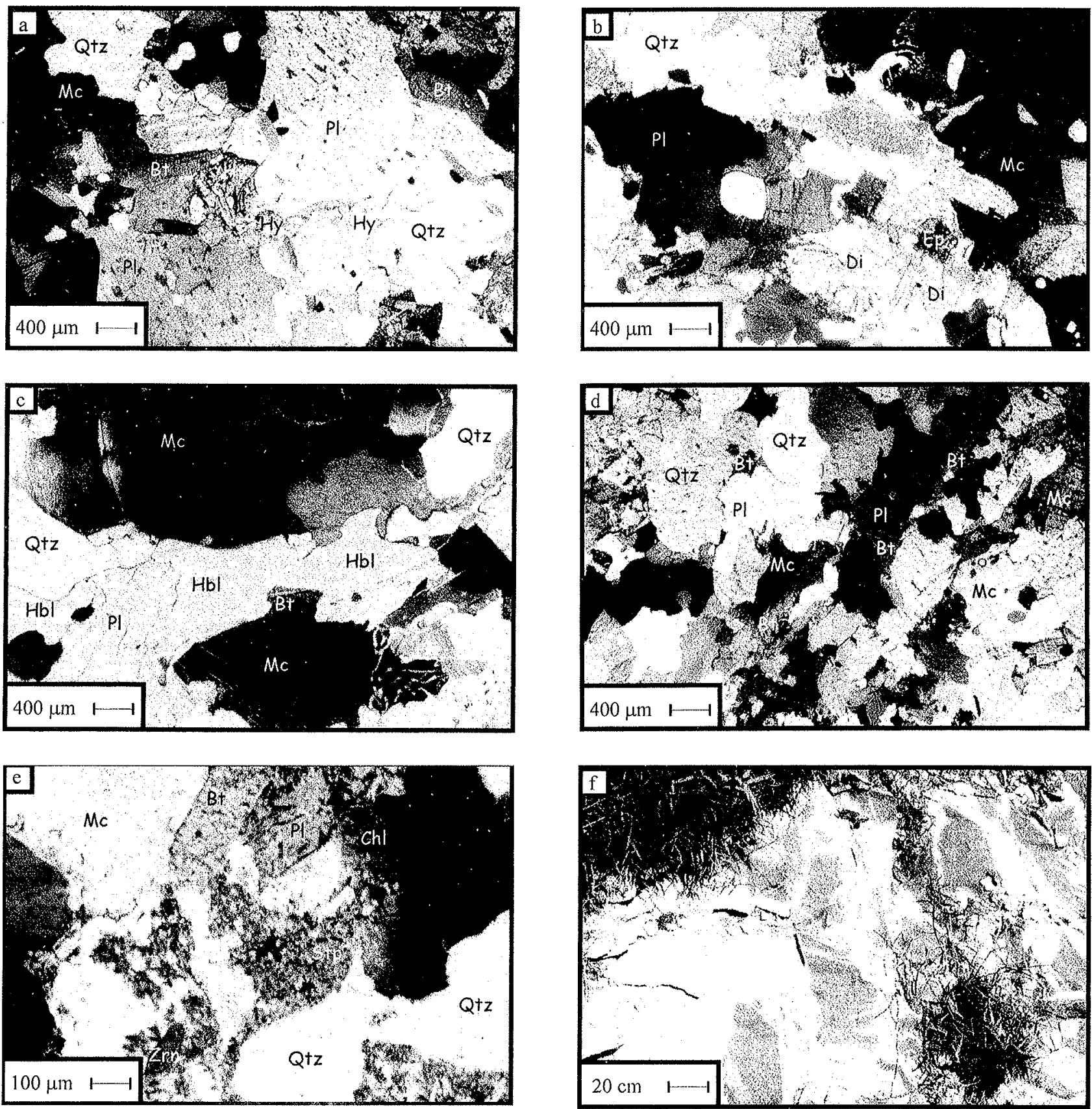

Figura 3 - Fotomicrografias das rochas e foto de afloranento das unidades litodêmicas do Complexo Metamórfico Campo Belo. a) Textura hétero-granoblástica do hiperstênio-biotita-hornblenda gnaisse tonalítico (Unidade Gnáissica), destacando-se a presenf̧a de plagioclásio antipertítico (Pol. X); b) Texturar granoblástica e lepidoblástica do hiperstênio-diopisídio-biotita gnaisse tonalítico (Unidade Gnáissica), destacando a transformação do diopisídio para biotita e epidoto (Pol. X); $c)$ Textura granoblástica e, subordinadamente, lepidoblástica e nematoblástica do hiperstênio-biotita-hornblenda gnaisse granítico da Unidade Gnáissica (Pol. X); $d+e)$ Textura granoblästica e, subordinadamente, lepidoblástica do hiperstênio-diopisídio-biotita gnaisse granítico (Unidade Gnáissica), destacando (fotomicrografia e) a transformação de biotita para clorita e estilpnomelano (Pol. X); $f$ ) Encraves anfibolíticos (Unidade Anfibolitica) na fase migmatítica das rochas da Unidade Gnáissica. A simbologia das fases minerais obedece ao padrão proposto por Kretz. (1983), ou seja: Ol=olivina, Or=ortoclásio; $M c=$ microclínio; $P l=$ plagioclásio; Qtz=quartzo; Ent=enstatita; Hy=hiperstênio; Di=diopisídio; Aug=augita; Sil=sillimanita; Grt=granada, Hbl=hornblenda; Bt=biotita; Chl=clorita; Ep=epidoto; Ms=nuscovita; Srp=serpentina; Esp=espinélio; Tc=talco; Srt $=$ sericita; Prl=pirofilita; Stp=estilpnomelano; Op=opacos; Zrn=zircão.

nas rochas das unidades gnáissica e metaultramáfica, que apresentam xenólitos de ambas. Além disso, esses diques invadem a Unidade Quartzítica e nota-se que tiveram a sua progressão lateral interrompida pelas rochas da Unidade Granítica (s.l.). As rochas gabronoríticas apresentam textura subofítica (Fig. 4c) e, algumas vezes, textura fluidal. As ripas de plagioclásio representam de 50 a $55 \%$ do volume total da rocha e mostram geminação polissintética. Hiperstênio (10-15\%) e augita (?; 15-20\%) são os piroxênios que sofrem transformação para hornblenda $(\sim 5 \%)$, no processo de uralitização, que vem acompanhada de quartzo $(\sim 5 \%)$ e opacos em pequenos grãos. Apatita e zircão ocorrem como fases acessórias

Unidade Granítica (s.I.) As rochas desta unidade têm ampla distribuição na região estudada. Podem ocorrer como diques de variadas dimensões ou como grandes corpos intrusivos (Fig. 2). Neste último caso, destacam-se duas ocorrências mais expressivas, uma situ- 

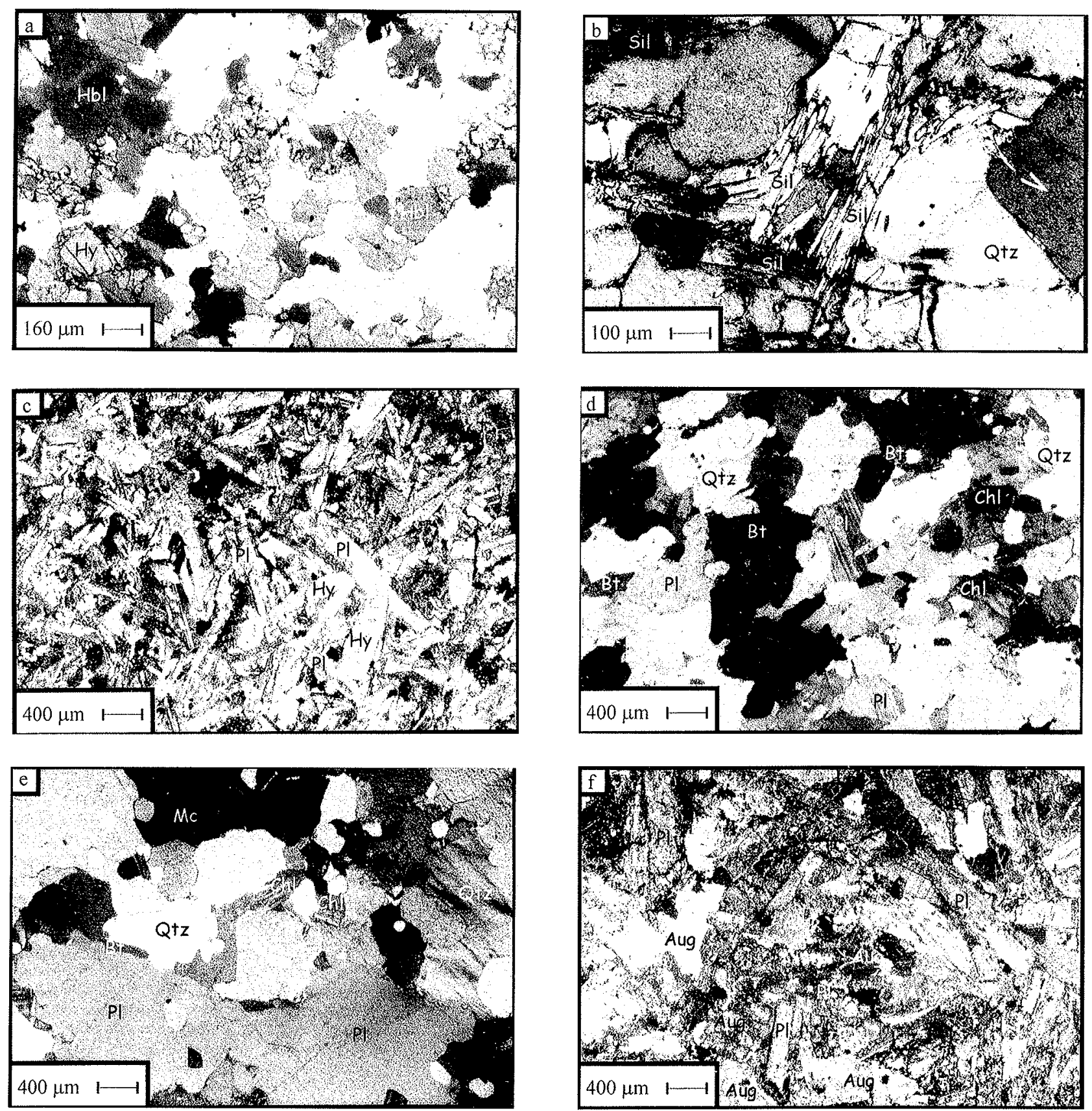

Figura 4 - Fotomicrografias das rochas das unidades litodêmicas do Complexo Metamórfico Campo Belo. a) Aglomerados de cristais, ora de hiperstênio ora de hornblenda, das rochas da Unidade Anfibolítica (Pol. /1); b) Arranjos texturais do tipo granoblástico e decussado (cristais de sillimanita) do granadasillimanita-quartzito da Unidade Quartzítica $(P o l, X) ; c)$ Textura subofitica das rochas da Unidade Gabronoritica $(P o l$. X); d) Texturas porfirítica, granítica e magmática fluidal do tonalito da Unidade Granítica, destacando-se a transformação de biotita para clorita (Pol. X); e) Texturas porfirítica e granítica do granito da Unidade Granítica, destacando-se a clorita formada às expensas da biotita (Pol. X); $f$ ) Textura ofítica das rochas da Unidade Gabróica (Pol. X). Simbologia das fases minerais como na Figura 3.

ada a noroeste da cidade de Campo Belo, onde interrompe a progressão de um dique de gabronorito e, outra, a sudoeste da cidade de Santo Antônio do Amparo. As rochas da Unidade Granítica (s.l.) podem ser classificadas como tonalito e granito.

TONALITO Este litotipo tem cor clara, em tons acinzentados, granulação média e apresenta texturas do tipo porfirítica, granítica e, algumas vezes, mostram um alinhamento marcante de minerais máticos e, mais subordinadamente, de quartzo e feldspato, caracterizando uma textura magmática fluidal (Fig. 4d). Ocorrem na forma de diques paralelos ao bandamento gnáissico, como é o caso da
Pedreira Fernão Dias. O plagioclásio é o constituinte principal ( $40 \%$ ), em algumas seções, mostra processos de sericitização e saussuritização. Porém, ainda é possível distinguir a geminação polissintética. O quartzo representa $30 \%$ do volume da rocha e o microclínio é o constituinte menor $(\sim 5-15 \%)$. A biotita $(\sim 15 \%)$ aparece orientada devido ao processo de fluxo magmático e mostra transformação para clorita (Fig. 4d). Titanita, rutilo e zircão são minerais acessórios.

GRANITO Este tipo petrográfico tem cor clara, em tons rosados ou esbranquiçados, granulação média e apresentam texturas porfirítica e 
granítica (Fig. 4e). Ocorrem, comumente, na forma de grandes corpos intrusivos nas rochas da Suíte Gnáissica. O microclínio é o constituinte principal ( $\sim 40-45 \%$ do volume total da rocha), aparece maclado segundo as leis da albita e do periclíneo e mostra grãos anédricos a subédricos. O quartzo perfaz 30-35\% do volume da rocha e ocorre como grãos anédricos. Plagioclásio é o constituinte menor $(\sim 15-20 \%)$ e mostra-se epidotizado e sericitizado. A biotita $(\sim 10-15 \%)$ é encontrada na forma de placas e transforma-se para clorita. A granada ocorre raramente, ao passo que, titanita, rutilo e zircão são as fases acessórias comuns.

Unidade Gabróica Os diques de gabro dessa unidade estão orientados, preferencialmente, segundo a direção N50-55W, cortam os diques da Unidade Gabronorítica, mas não mostram relações de intrusão com os granitóides. Apresentam texturas do tipo ofítica (Fig. 4f), subofítica e fluidal. O plagioclásio, maior constituinte da rocha (50$60 \%$ ), apresenta geminação polissintética e ocorre como cristais ripiformes, às vezes, saussuritizados. O clinopiroxênio (augita ?) perfaz de 25 a $30 \%$ do volume total da rocha e altera-se para hornblenda $(\sim 5 \%)$. Quartzo $(5 \%)$ e opacos ocorrem em pequenos cristais, resultantes da uralitização do piroxênio. Apatita e zircão são minerais acessórias, ocorrendo com freqüência.

DISCUSSÃO Metamorfismo A maior variabilidade metamórfica, encontrada na região em estudo, está registrada nas rochas das Unidades Gnáissica, Anfibolítica, Metaultramáfica e Quartzítica, que mostram paragêneses reliquiares da fácies granulito, superimpostas por paragêneses retrometamórficas das fácies anfibolito e xisto verde (Tab. 1). Em contraposição, são as rochas da Unidade Granítica e as rochas originadas a partir dos episódios de magmatismo máfico fissural (Unidades Gabronorítica e Gabróica) que têm a menor variabilidade metamórfica. Nesse caso, tais rochas apresentam as suas paragêneses e texturas ígneas originais e sobre elas desenvolvem-se, apenas, paragêneses secundárias de fácies xisto verde (Tab. 1). Consequentemente, a maioria das unidades litodêmicas do Complexo Metamórfico Campo Belo, na área em estudo, foram geradas ou submetidas a condições metamórficas de fácies granulito, em eventos anteriores a colocação crustal das rochas das Unidades Gabronorítica, Granítica $(s . l$. ) e Gabróica.

Dadas as características do metamorfismo de fácies granulito, acredita-se que as rochas da região em estudo foram geradas em ambientes crustais profundos (base de crosta), onde as condições de $P$ e $T$ variam, segundo Ellis (1987), entre os intervalos de $12 \pm 4 \mathrm{kbar}$ e 800 $\pm 100^{\circ} \mathrm{C}$. As paragêneses da fácies anfibolito retratam níveis crustais intermediários, onde imperam condições de pressão e temperatura moderadas e presença de fluídos hidratados. Já o metamorfísmo de fácies xisto verde ocorre em níveis crustais mais rasos e reflete baixas condições de pressão e temperatura.

Evolução tectônica Mundialmente, terrenos granulíticos, similares àqueles encontrados na região estudada, apresentam idades que vão do Paleoarqueano ao Neoproterozóico [e.g. Complexo Napier em
Enderby Land, Antártica - Black et al. (1983); oeste da Groenlândia Chadwick \& Coe (1976), Moorbath et al. (1975, 1986); Complexo Lewisian, noroeste da Escócia - Hamilton et al. (1979), Rollinson \& Windley (1980); Complexo Jequié, sudeste da Bahia - Figueiredo \& Barbosa (1992)]. Há também, terrenos granulíticos mais jovens, do Fanerozóico, situados no sul da Índia (Cinturão Khondalito) e no oeste do Sri Lanka (e.g. Kröner et al. 1987). Tais terrenos, bem como o Complexo Metamórfico Campo Belo, apresentam uma variedade mui to grande de rochas (ígneas e metamórficas), as quais estão geneticamente associadas. Contudo, no caso dos terrenos citados acima, são os gnaisses granulíticos que, na maioria das vezes, conseguem guardar a história mais pretérita e revelar os mecanismos e processos que foram responsáveis pela formação da crosta mais primitiva. Em alguns casos, esta crosta começou a ser formada em $4,0 \mathrm{Ga}$, conforme atestam os dados isotópicos dos gnaisses da região de Fyfe Hills (Complexo Napier, Black et al. 1983). Na região estudada, são os gnaisses de fácies granulito que têm as idades U-Pb (zircão-SHRIMP) mais antigas, da ordem de 3,2 Ga (Teixeira et al. 1996, 1998). Por outro lado, sabe-se que o acervo de dados radiométricos, obtidos por vários métodos geocronológicos [e.g., U-Pb (diluição isotópica), $\mathrm{Sm}-\mathrm{Nd}, \mathrm{Pb}-\mathrm{Pb}$ e $\mathrm{Rb}-\mathrm{Sr}$ ], indica que o principal episódio de acresção crustal da região ocorreu entre 3,2 e 3,1 Ga (Teixeira et al. 1998). Resta saber, agora, os mecanismos e a natureza dos processos tectônicos responsáveis pela geração dessa crosta primitiva e, depois, a idade do evento tectonotermal de fácies granulito. Orientando a discussão neste sentido, é importante resgatar a informação petrográfica das rochas da Unidade Anfibolítica que exibem coronas de augita a volta do hiperstênio. Esta feição é típica em rochas que seguiram trajetórias de resfriamento isobárico e desenvolve-se em resposta ao resfriamento, posterior ao pico metamórfico, sob pressões aproximadamente constantes (Ellis 1987, Harley 1989). Ao considerar-se este fato, implicase dizer que o pico metamórfico ocorreu numa crosta com espessura normal (da ordem de $30 \mathrm{~km}$ ), sob a atuação de um dos seguintes processos (e.g., Harley 1989): a) acresção magmática dentro e sob uma crosta oceânica ou continental preexistente; $\mathbf{b}$ ) extensão de uma crosta de espessura normal, com concomitante sob-acresção magmática; c) extensão de uma crosta de espessura normal, sem uma contribuição magmática adicional como principal fonte de calor externa; d) extensão de uma crosta previamente cavalgada em um cenário colisional ou de arco continental. Baseando-se nas implicações geradas por esta trajetória de resfriamento isobárico (e.g., Harley 1989), propõe-se que, para a formação da crosta continental primitiva da região estudada teve lugar um ou mais processos de subducção entre crostas oceânicas (primordiais ?), propiciando, assim, a fusão e a diferenciação magmática da astenosfera. A partir disto, os episódios de acresção magmática deram origem a um ou mais arcos magmáticos juvenis (Fig 5a). As sucessivas colagens de vários deles criaram as primeiras crostas continentais, que representariam os protólitos dos gnaisses e anfibolitos, ora discutidos.

Tabela I-Paragêneses minerais das unidades litodêmicas do Complexo Metamórfico Campo Belo na regiäo estudada.

\begin{tabular}{|c|c|c|c|c|}
\hline \multirow{2}{*}{$\begin{array}{c}\text { UNIDADES } \\
\text { LITODÊMICAS }\end{array}$} & \multicolumn{4}{|c|}{ PARAGÊNESES MINERAIS } \\
\hline & Primária & Fácies Granulito & Fácies Anfibolito & Fácies Xisto Verde \\
\hline Gnáissica & $?$ & $\operatorname{Or}(?)+\mathrm{Pl}+\mathrm{Qtz}+\mathrm{Hy} \pm \mathrm{Di}$ & $\mathrm{Pl}+\mathrm{Qtz}+\mathrm{Mc} \pm \mathrm{Hbl} \pm \mathrm{Bt} \pm \mathrm{Ep}$ & $\mathrm{Pl}+\mathrm{Qtz}+\mathrm{Mc}+\mathrm{Bt}+\mathrm{Chl} \pm \mathrm{Srt} \pm \mathrm{Stp}$ \\
\hline Anfibolítica & $?$ & $\mathrm{Hy}+\mathrm{Aug}(?)+\mathrm{Hbl}+\mathrm{Pl}$ & $\mathrm{Pl}+\mathrm{Qtz}+\mathrm{Hbl}+\mathrm{Bt}+\mathrm{Ep}$ & $\mathrm{Pl}+\mathrm{Qtz}+\mathrm{Chl}+\mathrm{Srt}$ \\
\hline Metaultramáfica * & $\mathrm{Ol} \pm \mathrm{En} \pm \mathrm{Hbl}(?)$ & $\mathrm{Ol} \pm \mathrm{En}+\mathrm{Spl}$ & $\mathrm{Ol}+\mathrm{En}+\mathrm{Hbl}$ & $\mathrm{Ol}+\mathrm{En}+\mathrm{Srp}+\mathrm{Tlc}$ \\
\hline Quartzítica & $?$ & $\mathrm{Qtz}+\mathrm{Sil} \pm \mathrm{Grt}$ & $\mathrm{Qtz}+\mathrm{Ms}$ & $\mathrm{Qtz}+\mathrm{Srt}+\mathrm{Prl}$ \\
\hline Gabronorítica & $\mathrm{Pl}+\mathrm{Hy}+\mathrm{Aug}(?)$ & & & $\mathrm{Pl}+\mathrm{Qtz}+\mathrm{Hbl}+\mathrm{Op}$ \\
\hline Granítica (s.l.) & $\mathrm{Mc}+\mathrm{Qtz}+\mathrm{Pl}+\mathrm{Bt} \pm \mathrm{Grt}$ & & & $\mathrm{Mc}+\mathrm{Qtz}+\mathrm{Pl}+\mathrm{Chl}+\mathrm{Ep}+\mathrm{Srt}$ \\
\hline Gabróica & $\mathrm{Pl}+\operatorname{Aug}(?)$ & & & $\mathrm{Pl}+\mathrm{Qtz}+\mathrm{Hbl}+\mathrm{Op}$ \\
\hline
\end{tabular}


a crosta oceânica (primordial ?)
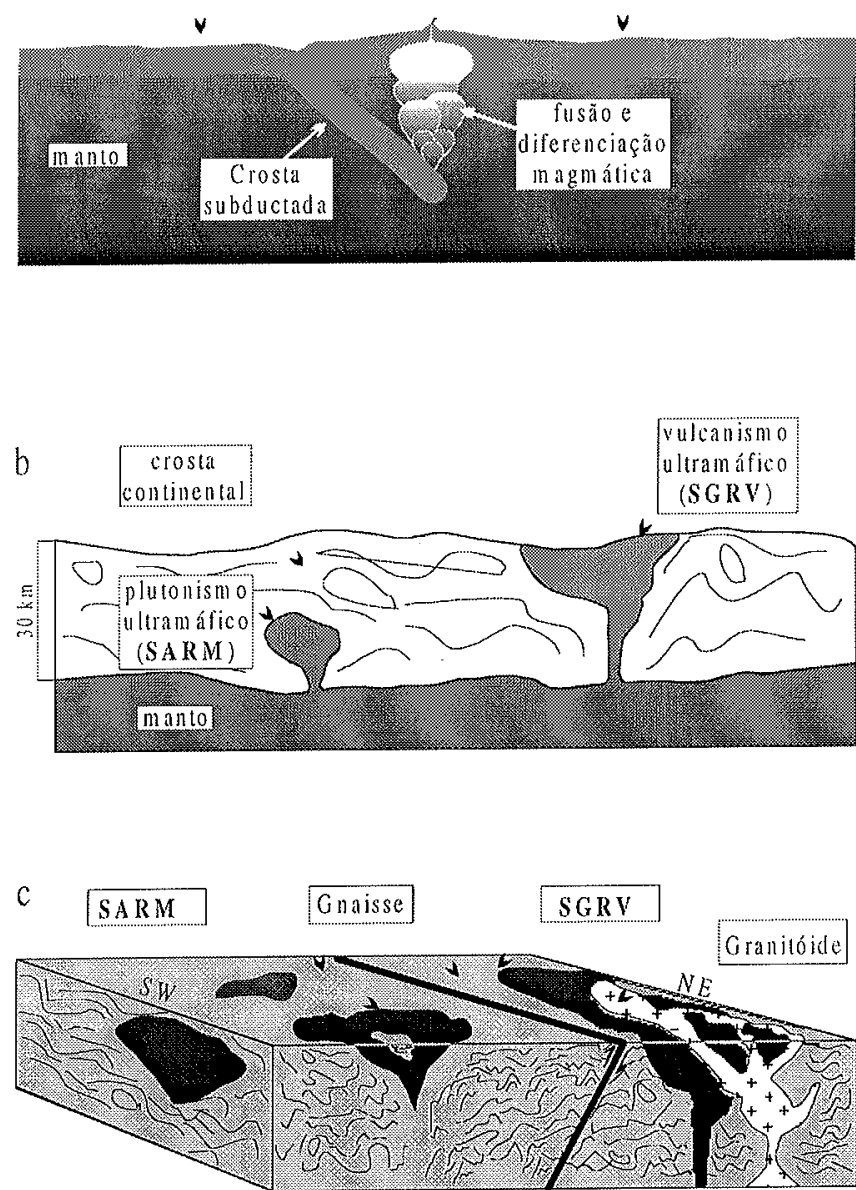

Figura 5-Seções diagramáticas ilustrando a gênese e evolução geológica do Cráton Säo Francisco Meridional: a) origem dos protólitos dos gnaisses e anfibolitos durante a formação da crosta continental primitiva; b) magmatismo ultramáfico servindo como fonte de calor externa para o metamorfismo granulítico das rochas gnáissicas e anfibolíticas; $c$ ) zona de fraqueza crustal justapondo temporalmente rochas de alto e baixo graus metanórficos.

Caso estes protólitos tenham permanecido em profundidade, depois de um certo período de tempo, a sua mineralogia seria reequilibrada para condições de fácies granulito. Tal situação poderia ter sido intensificada ou prolongada, se temperaturas crustais mais elevadas se mantivessem em virtude de uma fonte de calor externa, oriunda de outros episódios termais, tais como, magmatismo máfico-ultramáfico e ou novos diferenciados félsicos, introduzidos sob (ou na) crosta em formação (Fig. 5b). Os cenários tectônicos mais apropriados para que o aquecimento magmático viesse a produzir granulitos, seriam; a) ambientes extensionais, tais como rifts continentais (Sandiford \& Powell 1986) e b) ambientes compressionais, como arcos do tipo Andino (Bohlen 1986). Outros condicionantes para a variação térmica seriam o aquecimento gerado, localmente, por cisalhamento e a passagem de fluídos anidros. Considerando esta crosta em formação e a possibilidade do evento metamórfico de fácies granulito estar relacionado a fontes externas de calor (episódios magmáticos), o magmatismo que responde pela geração das rochas da Seqủência Acamadada Ribeirão dos Motas (SARM) pode ter tido a sua parcela de contribuição no metamorfismo (e.g. intensificar ou prolongar) nas rochas das Unidades Gnáissica e Anfibolítica (Fig. 5b). Por outro lado, como indicam as suas paragêneses minerais, a exemplo do que aconteceu com as rochas gnáissicas e anfibolíticas, as rochas metaultramáficas foram reequilibradas para fácies granulito devido a sua posição crustal (base de crosta). Este par cíclico (metamorfismo e episódios magmáticos) caracteriza parte do evento de fácies granulito na região, o qual restringe-se ao Neoarqueano, pois, a idade do magmatismo ultramáfico não deve ser posterior a $2,75 \mathrm{Ga}$, que foi o valor encontrado por uma errócrona Sm-Nd (Carneiro et al. 1997b). Se essa for a idade real dessas rochas, esse magmatismo poderia ser, regionalmente, correlacionado à unidade máfica-ultramáfica basal do Supergrupo Rio das Velhas (Grupo Quebra Ossos, Schorscher 1979) que ocorre no Quadrilátero Ferrífero (Carvalho Júnior et. al. 1998). Lá, este magmatismo está relacionado a uma das fases do Evento Tectonotermal Rio das Velhas, ocorrido entre 2,78 e 2,70 Ga (Carneiro 1992, Carneiro et al. 1998b, Endo et al. 1996b). As rochas da Unidade Quartzítica, por sua vez, têm a natureza de seus processos genéticos obscurecidos pela falta de dados, devido aos poucos afloramentos até então. No entanto, dois processos tectônicos poderiam responder pelo seu metamorfismo de alto grau: a) soterramento crustal até profundidades entre $15-30 \mathrm{~km}$ e b) aumento do gradiente termal para valores da ordem de 700 a $800^{\circ} \mathrm{C}$. Tais processos poderiam, por exemplo, estar relacionados à atuação de grandes falhamentos imbricados, que teriam conduzido o protólito destas rochas para a crosta inferior, onde as condições de pressão e temperatura permitiram o estabelecimento da paragênese de fácies granulito. Para Corrêa da Costa (1999) as rochas quartzíticas seriam correlacionáveis ao Grupo Maquiné (Schorscher 1979). Visto que as rochas das Unidades Gnáissica, Anfibolítica, Metaultramáfica e Quatzítica passaram pelas mesmas condições metamórficas, é possível especular que o metamorfisıno de fácies granulito tenha prevalecido até $2,8 \mathrm{Ga}$, independente do processo tectônico responsável pela formação da crosta. Isto porque os dados isotópicos Rb-Sr e Pb-Pb de Teixeira et al. (1996; 1998), obtidos em gnaisses e migmatitos, situam-se no intervalo entre $3167 \pm 213 \mathrm{Ma}$ $2767 \pm 29 \mathrm{Ma}$, apontando, portanto, para um ou mais eventos tectonotermais, no decorrer dos quais a crosta, em estudo, sofreu um ou mais processos de homogeneização ou re-homogeneização isotópica. As Unidades Gabronorítica (comelacionável à Suíte Básica Norítica com idade isocrônica Sm-Nd de 2,66 Ga; Pinese 1997) e Granítica (até agora destituída de geocronologia) relacionariam-se às fases magmáticas tardias do Evento Tectonotermal Rio das Velhas. A Unidade Gabróica (correlacionável à Suíte Básica com idade isocrônica Rb-Sr de 1,89 Ga; Pinese 1997), por sua vez, estaria relacionada à colagem do Cinturão Mineiro ao pós-país do orógeno transamazônico, posicionado a sudeste da região estudada. $O$ metamorfismo das Unidades Gabronorítica, Granítica e Gabróica não está, aparentemente, relacionado a qualquer evento tectônico importante da história evolutiva do Cráton São Francisco Meridional. Acredita-se, no entanto, que esse metamorfismo esteja associado ao soerguimento crustal, que é uma consequiência natural do reajustamento isostático da crosta continental soerguida. Para Ellis (1987) o soerguimento de rochas, até atingirem o nível de exposição numa crosta de espessura normal, levaria entre 50 e $200 \mathrm{Ma}$. Como este metamorfismo afeta as rochas da Unidade Gabróica, que são paleoproterozóicas, o soerguimento crustal deve ser posterior ao magmatismo que as gerou e, talvez, relacionado à formação das ombreiras da bacia neoproterozóica que abarcou os sedimentos do Supergrupo São Francisco. Um outro fato interessante é que, à semelhança do que ocorre no Quadrilátero Ferrífero, tem-se na região em estudo a seguinte seqüência litodêmica: gnaisses, rochas metaultramáficas e quartizito. Mas em contraposição ao Quadrilátero Ferrífero, as rochas das Unidades Metaultramáfica (SARM) e Quartzítica têm paragêneses metamórficas da fácies granulito. Esse contraste, em relação à intensidade dos eventos metamórficos que afetaram uma e outra região, pode significar que tais regiões representam níveis crustais distintos e justapostos temporalmente. Tal justaposição ocorreu, possivelmente, no Arqueano e deve relacionar-se a uma zona de fraqueza regional, limítrofe entre as duas regiões, mas ainda não suficientemente descrita (Fig. 5c).

Agradecimentos Os autores externam seus agradecimentos à FAPEMIG (processos CRA 827/96 e 2220/96) pelo apoio à pesquisa; ao $\mathrm{CNPq}$ (pela bolsa de produtividade de $\mathrm{MAC}$ ); aos revisores anôni mos da RBG pelas sugestões e, em especial, àquele que teceu severos comentários que muito contribuíram para o melhoramento do texto. 


\section{Referências}

Alkmim, F. F. \& Marshak S. 1998. Transamazonian orogeny in the Southern São Francisco Craton region, Minas Gerais, Brazil: evidence for Paleoproterozoic collison and collapse in the Quadrilátero Ferrífero. Precambrian Research, 90:29-58.

Alkmin F. F. Brito Neves B. B., Alves J. A. C. 1993. Arcabouço tectônico do Cráton do São Francisco: uma revisão. In: O Cráton do São Francisco. J. M. L. Dominguez \& A Misi (eds), SBG, SGM-BA, p. 45-62

Barbosa O. 1954. Resumo da Geologia do Estado de Minas Gerais. Boletim do Departamento de Serviços Geográfico e Geológico, 3:1-40.

Black L. P., James P. R., Harley S. L. 1983. The Geochronology, Structure and Metamorphism of the Early Archaean Rocks at Fyfe Hills, Enderby Land, Antarctica. Precambrian Researsh, 21:197-222.

Bohlen S. R. 1986. Pressure-temperature-time paths and a tectonic model for the evolution of granulites. Joumal of Geology; 95:617-632.

Bucher K. \& Frey M. 1994. Petrogenesis of Metamorphic Rocks. Springer, Berlin, 318p.

Carneiro M. A Teixeir W Carvalho Júnior Y M de Fernandes R. A 1998a Sialic crust as a part of the Archean greenstone belt basement, evidence from the Bonfim Metamorphic Complex, Quadrilátero Ferrífero, Brazil. Revista Brasileira de Geociências, 28:71-82.

Carneiro M A Nalini J H A Teixeira W Oliveira A H de, Corrêa da Costa P. C. Carvalho Júnior I M de, Franco A S. P. Camporez J. A. P. 1998b. The tectonic Carvalho Junior $1 . M$. de, Franco A. S. P., Camporez J. A.P. 1998b. The tectonic assembly of the southern São Francisco Craton, Brazil: Facts, fictions and new approaching. In: Internat

Carneiro M. A Nalini Jr H. A., Bilal E., Carvalho Júnior I. M. de, Teixeira W., Moutte J. 1997a. A seqüência Acanadada de Ribeirão dos Motas, Minas Gerais, Brasil. In: X Semana de Geoquímica, IV Congresso de Geoquímica dos Países de Língua Portuguesa. Braga. Actas, p. $31-33$.

Carneiro M. A., Teixeira W., Carvalho Júnior I. M. de, Oliveira A. H. de, Fernandes R. A 1997b. Archean Sm/Nd isochron age from the Ribeirão dos Motas layered rocks sequence, Southern São Francisco Críton, Brazil. In: South-American Symposium on Isotope Geology. Campos do Jordão. Extended Abstracts, p. 63-64

Carneiro M. A., Carvalho Júnior I. M de, Fernandes R. A., Teixeira W. 1997c. Geologia de parte do segmento crustal situado entre as cidades de Oliveira, Campo Belo e Santana do Jacaré. MG. In: Simpósio de Geologia de Minas Gerais, IX., Ouro Preto. Anais, p37.

Canciro M A Teixeira W Nalini J $\mathrm{H}$ A Bilal E Oliveira A $\mathrm{H}$ de Carvalho Júnior I. M de. 1996a. Archean ultramafic-mafic magmatism in the Southern São Francisco Cráton (Campo Belo Complex): Preliminary petrographic and geochemical results. In: Symposium on Archean Terranes of the South American Plataform, Brasília. Anais, p32-33.

Carneiro M. A., Teixeira W., Noce C. M., Fernandes R. A. 1996b. Archean growth processes in the Quadrilátero Ferrifero: A geochronological U-Pb and Sm-Nd approach to the Rio das Velhas Event (2780 - 2700 Ma). In: Symposium on Archean Terranes of the South American Plataform. Brasília. Anais, p59-60.

Carneiro M. A. 1992. O Complexo Metamórfico Bonfim Setentrional (Quadrilatero Fetrifero, Minas Gerais): Litoestratigrafia e Evolução Geológica de um Segmento de Crosta Contuental do Arqueano. Inst de Geociências, Universidade de São Paulo, São Paulo, Tese de Doutoramento. 233p.

Carvallıo Júnior I. M. de \& Carneiro M. A. 1999. Sequêencia Acamadada de Ribeirão dos Motas: Uma ocorrência de rochas ultramáficas plutônicas no Cráton São Francisco Meridional, In: Simpósio de Geologia de Minas Gerais e Centro Oeste, X, Brasília. Residionos, p36.

Carvalho Júnior I. M. de Carneiro M. A., Nalini J: H. A., Teixeira W. 1998. Seriam as rochas da Sequiência Acamadada de Ribeirão dos Motas o correspondente plutônico do magmatismo ultramáfico do Greenstone Belt Rio das Velhas?. In: Congresso Brasileiro de Geologia, XL, Belo Horizonte. Restumos, p68

Carvalho Júnior I. M. de, Carneiro M. A., Suíta M. T. de F., Teixeira W. 1997. Antíbólio intercúmulos na Sequiência Acamadada de Ribeirão dos Motas: um modelo petrogenético para sua origem. In: Simpósio de Geologia de Minas Gerais, IX, Ouro Preto. Ancis, p38-39.

Chadwick B. \& Coe K. 1976. New Evidence Relating to Archaean Events in Southern West Greenland. In: B. F Windley (ed.) The Early History of the Earth. London. John Wiley \& Sons, p203-211.

Corrêa da Costa P. C. 1999. Episódios de Fomação de Crosta Cominental Arqueana no Cráton Säo Francisco Meridional: Um exemplo a partir da Região de Candeias Cráton Säo Francisco Meridional: Um exemplo a partir da Regiano de CandetasFederal de Ouro Preto, Ouro Preto, Dissertação de Mestrado, 132p.

Dorr II J. V. N. 1969. Physiographic, Stratigraphic and Structural Development of the Quadrilátero Ferrifero, Minas Gerais, Brazil. U.S G S. Professional Paper, 641(A). $110 \mathrm{p}$.

Dorl II J. V. N., Gair J. E., Pomerone J. B., Rynear'son G. A. 1957. Revisão Eestratigráfica Precambirana do Quadrilátero Ferrífero. Div. Fom. Prod. Min., Avulso, n'81, $31 \mathrm{p}$.

bert H. 1958. Discordâncias Precambrianas em Carandaí, Minas Gerais. Boletim da Divisão de Geologia e Mineralogia, 183:1-48.

Ebert H. 1956. Relatório. Relatório Anual da Divisão de Geologia e Mineralogia, 1955:6281.

Ellis D. J. 1987. Origin and Evolution of Granulites in Normal and Tickened Crusts. Geology, 15: 167-170

Endo 1. 1997. Regimes Tectônicos do Arqueano e Proterozóico no Interior da Placa Sanfranciscana: Quadrilárero Ferrifero e Adjacências, Minas Gerais. Inst. de
Geociências, Universidade de São Paulo, São Paulo, Tese de Doutoramento, 243p.

Endo I. \& Carneiro M. A. 1996 a. O Regime Tectônico do Neoarqueano no Quadrilátero Ferrífero: um Modelo Transpressional. In: Congresso Brasileiro de Geologia., 39, Salvado: Anais, 1:414-416.
Endo I., Carneiro M. A., Machado R. 1996b. O Complexo Metamórfico Baçâo: Um Elemento Estrutural Anisotrópico na Deformaçāo do Supergrupo Rio das Velhas - Q. F.

Fernandes R. A. \& Carneiro M. A. 1999. Hiperstênio Gnaisses do Complexo Metamórfico Campo Belo, MG: Aspectos Petrotectônicos Gerais. In: Simpósio de Geologia de Minas Gerais e Centro Oeste, X. Brasília. Restumos, p49.

Fernandes R. A., Carneiro M. A... Carvalho Jr I. M. de, Teixeira W. 1998. Eventos de Superimposição Metamórfica nas Rochas do Complexo Metamórfico de Campo Belo, MG. In: Congresso Brasileiro de Geologia., 40, Belo Horizonte. Resumos, p57.

Fernandes R. A., Carneiro M. A., Teixeira W. 1997. O metamorfismo das rochas da região de Santana do Jacaré, MG. In: Simpósio de Geologia de Minas Gerais, IX., Ouro Preto. Anais, p45-46.

Figueiredo M. C. H. \& Barbosa J. S. F. 1992. Terrenos Metamórficos de Alto Grau do Cráton do São Francisco. In: II Simpósio Sobre o Cráton do São Francisco, Salvador. Trabalhos, p63-84.

Hamilton P. J., Evensen N. M., O'nions R. K. 1979. Sm-Nd Systematics of Lewisian Gneisses: Implications for the Origin of Granulites. Nature, 277:25-28.

Harley S. L. 1989. The Origins of Granulites: a Metamorphic Perspective. Gerl. Mag., 126 (3): 215-247.

Hattin D. E 1991. Lithodemes, suites, supersuites, and complexes: intrusive, metamorphic, and genetically mixed assemblages of rocks now embraced by North American Code of Stratigraphic Nomenclature. Precambrian Research, 50:355-357.

Kretz R. 1983. Symbols for rock-forming minerals. American Mineralogist, 68(1-2): 277 279.

Kröner A., Williams I. S., Compston W., Baur N., Vitanage P. W., Perera L. R. L. 1987. Zircon Ion Microprobe Dating of High Grade Rocks in Sri Lanka. Journal of Geology, 95:775-791

Machado Filho L., Ribeiro M. W., Gonzalez S. R., Schenini C. A., Santos Neto A., Palmeira R. C. B., Pires J. L., Teixeira W., Castro H. E. F. 1983. Projeto RADAMBRASIL. Folha SF.23/24, Rio de Janeiro/Vitória. Vol. 32, p:27-304.

Moorbath S., Taylor P. N. Jones N. W. 1986. Dating the Oldest Terrestrial Rocks - Fact and Fiction. Chenical Geology, 57:63-86.

Moorbath S., O'nions R. K., Pankhurst R. J. 1975. The Evolution of Early Precambrian Crustal Rocks at Isua, West Greenland - Geochemical and Isotopic Evidence. Earth and Planetay. Science Letters, 27:229-239.

Oliveira A H de 1099 . Evolusão Tectônica de um Segmento Crustal Arcueano do Cráton São Francisco Meridional Departamento de Geologia da Escola de Minas, Universidade Federal de Ouro Preto, Ouro Preto, Dissertação de Mestrado, 104p.

Oliveira A l de 1954. As Atividades do Departamento Nacional de Produção Mineral. Engenharia, Mineração e Metalurgia, 19:91-92.

Pinese J. P. P. 1997. Geoquímica, geologia isotópica e aspectos petrológicos dos diques máficos pré-cambrianos da Região de Lavras $(M G)$, Porção sul do Cráton do São Francisco. Inst. de Geociências, Universidade de São Paulo, São Paulo, Tese de Doutoramento, $178 \mathrm{p}$

Pires F. R. M. 1977. Geologia do Distrito Manganesifero de Conselheiro Lafaiete. Minas Gerais. Instituto de Geociências, Universidade Federal do Rio de Janeiro, Rio de Janeiro, Dissertação de Mestrado, 344p.

Rollinson H. R \& Windley B. F. 1980. An Archaean Granulite-Grade Tonalite-TrondjemiteGranite Suite from Scourie, Nw Scotland: Geochemistry and Origin. Contributions to Mineralogy and Petrology, 72:265-281

Rynearson G A et al 1954 Contato Basal da Série Minas na Parte Ocidental do Ouadrilátero Ferrifero, Minas Gerais, Brasil. Avulso da Divisão de Geologia e Mineralogia, 34:1-18.

Sandiford M \& Powell R. 1986. Deep crustal metamorphism during continental extension modern and ancient examples. Earth Planet. Sci. Lett., 59:177-191.

Schorscher H. D. 1979 . Evolução Arqueana e Proterozóica do Quadrilátero Ferrífero e de Partes Meridionais da Serra do Espinhaço. In: Simpósio sobre a Geologia do Cráton Săo Francisco e de suas Faixas Marginais, 1, Salvador, Restuntos.

Streckeisen A. 1974a. Classification and Nomenclature of Plutonic Rocks. Geol Rundschau, 63:773-786.

Streckeisen A. 1974b. How should charnockitic rocks be named? Géologie des domaines cristallins. Centenaire de la Société Géologique de Belgique. Liege, 349-360.

Teixeira W. Cordani U. G., Nutman A. P., Sato K. 1998. Polyphase Archean evolution in the Campo Belo Metamorphic Complex, Southern São Francisco Crálon, Brazil SHRIMP U-Pb evidence. Joumal of South American Earth Sci.. 11:279-290.

Teixeira W. Carneiro M. A., Noce C. M., Machado N., Sato K., Taylor P. N. 1996. Pb, St and $\mathrm{Nd}$ isotope constraints on the Archean evolution of gneissic-granitoid complexes and $N$ isotope constraints on the Archean evolution of gneissic-granitoid con

Turner F J 1981 Metamorphic Petrology. McGraw-Hill Book Co., 2 edição, 524p.

Winkler H. G. F. 1981. Petrogênese das Rochas Metamónficas. Co-ediçóes URGS Trad. 4 Ed

Yardley B. W. D. 1993. Introdução à Petrologia Metcomófićca. Tradução ed. 1989. Ed. Univ. Brasília, 340p.
Manuscrito A-1118

Recebido em 20 de agosto de 1999

Revisão dos autores em 15 de agosto de 2000 Revisão accita em 20 de agosto de 2000 